\title{
Modification of polymeric materials for 3D printing of external panels of nanosatellites
}

\author{
Dariya Isaeva ${ }^{1}$, Fedor Simankin ${ }^{1,}$, Yuriy Doncov ${ }^{1}$, and Arkadiy Simankin ${ }^{2}$ \\ ${ }^{1}$ National Research Tomsk Polytechnic University, 634050 Tomsk, Russia \\ ${ }^{2}$ Tula State University, 300012 Tula, Russia
}

\begin{abstract}
The results of mechanical testing of plastic samples, produced by injection molding and 3D printing are shown. Strength properties of filled and non-filled polymers are compared. The applicability of 3D printing technology with filled polymer materials of external panels is evaluated.
\end{abstract}

\section{Introduction}

One of the active developing areas of spacecraft engineering [1-2] attracting large investments is the creation of miniature satellites or nanosatellites (spacecraft weighing 1$10 \mathrm{~kg}$ ) including the so-called "student" satellites. These satellites as usual are made base on 'CubeSat' standard. This standard was developed by the researchers from California Polytechnic and Stanford universities. It is special standard for small cheap satellites, which are suitable for academic and educational purposes. Using of this standard gives the opportunity to place unique products in the same type of launchers containers thereby increasing the payload of rocket. However, despite significant levels of investment in the new industry all satellites are objects of single-unit production. Each satellite has unique design and technological solutions.

One of the modern directions of production development is advanced materials and technologies using. For example, in 2016 nanosatellite 'TPU-120' was sent to the International Space Station. External panels of this device was made of polymeric material using additive technology [3]. 'Honda Motor' together with 'Kabuki' (Japanese company specializing in additive technologies) has announced the release of a mini-electric vehicle 'Micro Commuter' with freestanding elements produced by 3D printer [4].

\section{Materials properties comparison}

Polymeric materials are increasingly used to create basic items for different purposes. This is because the plastic parts are much lighter analogues made of aluminium alloys. At the same time, the strength of the modified polymeric material is often the same as the metal analogues. A serious drawback of polymeric products is the need of using expensive and technologically complex equipment. In the case of a single-unit production, the price of the

* Corresponding author: simankinfa@tpu.ru 
product significantly increases. Additive technologies allow to create parts of a very complex shape without excessive rigging. The cost of the product obtained in this way is already much lower.

However, this technology has drawbacks. The products have lower strength characteristics [5-6]. This is due to technology, since the seal material is applied in layers. Firstly, "solid-state" virtual product model is divided into layers with simple thickness in a special program 'Slicer'. The layers are formed while moving in the working plane of the Hot-End nozzle, which injects molten polymer. The nozzle moves in the required manner to the coordinates $\mathrm{X}$ and $\mathrm{Y}$ and forms a layer of any degree of complexity. Then there is a shift of the head in the Z-axis direction by an amount equals to the thickness of the layer. The resulting product has the property of anisotropy. The maximum strength should be observed only in the direction corresponding to the axis of the strand (machine direction), extruded from the head (Figure 1, a). The next strand is laid parallel after some time. Thus, strength in the transverse direction is provided only by the strands sticking surfaces. Wherein the adhesion of adjacent strands depends on temperature and is heterogeneous in length. For example, on the rod with length $\mathrm{L}$ and width $\mathrm{B}$ there are some characteristic sections I, II and III (Figure 1, b). Sections II and III have more strength than section I since the temperature of adjacent strands is high in this area and the strands clump together in a very durable material. After a certain threshold the surface temperature is insufficient for reliable adherence and strength for the rest of the plot strands is not high enough ((Figure 1, c). In the $\mathrm{Z}$-axis direction, material has the lowest strength, especially if the area of the layer is large and the solidification of the material starts at high temperature. In this case, the surface of the strands is too cold to allow reliable of adhesion between adjacent strands. There is the need for additional heating of the surface of the printed layer before applying the next. In addition, under certain print modes the diameter of the strands is insufficient for fulfilling voids, i.e., material forms with stretched longitudinal cavities. Such material should be considered as orthotropic composite plastic, and the simulation of its properties can be carried out according to [8-11].

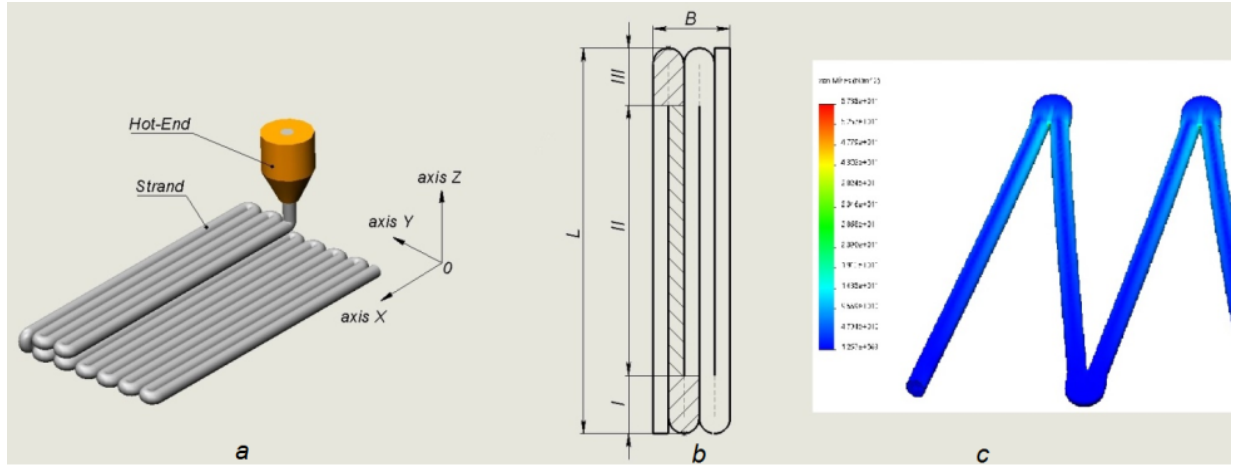

Fig. 1. Anisotropy of mechanical properties of material obtained by $3 \mathrm{D}$ printing.

The external panels of nanosatellites are designed to operate in very severe conditions of outer space. They should ensure maximum protection of the filling of the satellite. One of the perspective directions is the material reinforcement by carbon fiber. Reinforcement can be done with short fibers (filling) or a continuous carbon fiber. The axis of continuous fiber ccorresponds the axis of the extruded strand. Work on the creation of $3 \mathrm{D}$ printers enabling the printing of reinforced plastic is known [12]. However, printing with continuous reinforcement requires the creation of a fundamentally new type of equipment.

Despite the fact that continuous reinforcement does not solve the fundamental problem with the interlayer adhesion, the mechanical strength in the main direction increases 
significantly, making this method of obtaining body parts for nanosatellites very attractive. Increasing the strength in other areas can be provided by technology or software - for example, a partial shift of the elements of the layer on the Z-axis (software method implemented by the program slicer) or short-term local heating or cooling sections of the created layer (the technological method, requires the installation of additional equipment on the printer head).

\section{Tests}

The mechanical testing for evaluation of appropriate method of polymer modification was carried out. The samples were made from ABS-M30 plastic. Three different technologies had used for production of simples -injection molding (Figure 2, a) in the pressing chamber and the two methods of 3D printing. Samples of the resulting 3D printing have a structure formed by stacking of the strands in different ways along the direction of tensile load application (longitudinal strands) (Figure 2, b) and transversely to the direction of loading (transverse-strands) (Figure, $2 \mathrm{c}$ ). The samples were subjected to tension at a speed of 5 $\mathrm{mm} / \mathrm{min}$ until complete destruction on the testing machine Gotech AI-7000M. The test results are shown in the chart (Figure, 3). Curve 1 corresponds to the average strength of samples obtained by injection molding. Curve $2-$ the specimens printed on a $3 \mathrm{D}$ printer with longitudinal strands, curve 3 - the specimens printed on a $3 \mathrm{~d}$ printer with the transverse strands

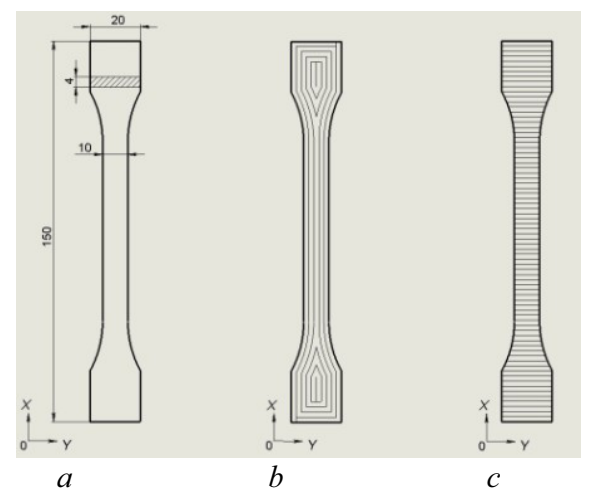

Fig. 2. Samples for mechanical testing.

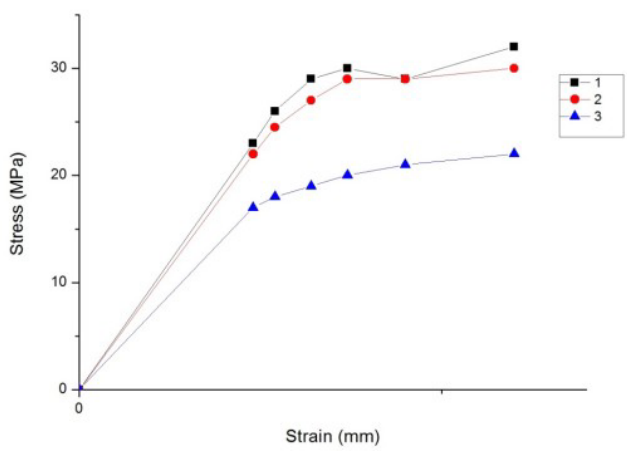

Fig. 3. Diagram of stress-strain in tension for the samples obtained in various ways: 1 -injection molding $2-3 \mathrm{~d}$ print with the direction of the strands parallel to the applied load (longitudinal), $3-3 \mathrm{~d}$ printing with the direction of the strands perpendicular to the applied load (transverse). 
The graph shows that the samples obtained by injection molding and printed samples with longitudinal strands (along the X-axis) differ slightly (less than 5\%). This drop in strength is related with the reduction in cross sectional area due to the presence in the samples stretched longitudinal cavities. Specimens with transverse arrangement of the strands (along the Y axis) have a lower strength (more than 20\%). Thus, we can conclude that in this case the strength of the sample was determined by the strength of sticking of strands.

Comparison of mechanical characteristics of pure and composite (filled) materials [13] shows that the filled material has greater value of tensile strength and, as mentioned earlier, is characterized by a high degree of isotropy of mechanical properties. However, filled materials have the property of brittle fracture. That is not an advantage for device body. In the event of impact, such detail is rather split up to complete destruction, while the detail of the non-filled polymer has only permanent plastic deformation.

The strength of the printed composite sample, printed from the combination of a continuous fibers and plastic material as a binder is not possible to estimate because of open data technologies absence. The assumption that the strength of such sample is determined by the strength of the reinforcing fibers can be made in this case. The strength of the common carbon fiber materials now comes to $4000 \mathrm{MPa}$. In this case, product can have strength at least several times higher than the product of the non-filled plastic. The polymeric binder provides the printed product with elastic properties, allowing minimizing the effects of impact on the object. In some cases, it may be applied to the simultaneous reinforcement of short fibers and continuous central fibers.

\section{Conclusions}

Tough requirements to products used in outer space can be met using composite material reinforcement by carbon fibres. Performed mechanical testing of samples obtained by different methods (injection molding and 3D printing) show that the transverse arrangement of the material strands decreases strength characteristics to $20 \%$. At the same time, strength increases in the reinforcement of the polymeric material with carbon fibres. This allows making a conclusion about the applicability of additive technologies for the manufacture of external panels for nanosatellites of polymeric material with central reinforcement strands of continuous carbon fiber.

\section{References}

1. K. Mertins, V. Ivanova, N. Natalinova, M. Alexandrova, MATEC Web of Conf. 48, 06002, (2016)

2. K. Mertins, V. Ivanova, MATEC Web of Conf. 37, 01025 (2015)

3. Tomsk-TPU-120, the first $3 D$ printed CubeSat Mission, URL : https://directory.eoportal.org/web/eoportal/satellite-missions/t/tomsk-tpu-120

4. Honda and Kabuku Inc., URL : http://www.conceptcarz.com/z26617/Honda-MicroCommuter.aspx

5. B.A. Lyuckshin, Computer simulation and design of composites (Pub. house of the Sib.branch of the RAof S., 2015)

6. V. Dmitriev, Y. Britova, MATEC Web of Conf. 48, 01005 (2016)

7. Yu. Britova, V. Dmitriev, T. Kostyuchenko, IOP Conference Series: Materials Science and Engineering 132(1), 012011 (2016) 
8. N.A. Kupriyanov, F.A. Simankin and K.K. Manabaev IOP Conference Series: Materials Science and Engineering 124, 012100 (2016)

9. A.A. Svetashkov, N. A Kupriyanov and K. K Manabaev, Fizicheskaya mezomechanika 18(6), 57 (2015)

10. A.A. Svetashkov, N.A Kupriyanov and K.K Manabaev, 2016 Key Engineering Materials 685, 206 (2015)

11. F.A. Simankin, G.R. Ziyakaev, I.V. Kuznetsov, R.E. Lushnikov, IOP Conference Series: Materials Science and Engineering 124(1), 012072 (2016)

12. Xiaoyong Tian, Tengfei Liu, Chuncheng Yang, Qingrui Wang, Dichen Li, Composites: Part A 88 (2016)

13. Metody ispytanij polimernyh materialov OOO «KOMEF», URL : http://www.komef.ru/metodisppolimer.pdf (in Russian) 